\title{
Variations in cell surfaces of estrogen treated breast cancer cells detected by a combined instrument for far-field and near-field microscopy
}

\author{
P. Perner ${ }^{\mathrm{a}, *}$, A. Rapp ${ }^{\mathrm{a}}$, C. Dressler ${ }^{\mathrm{b}}$, L. Wollweber ${ }^{\mathrm{a}}$, J. Beuthan $^{\mathrm{b}}$, K.O. Greulich ${ }^{\mathrm{a}}$ and M. Hausmann ${ }^{\mathrm{a}, \mathrm{c}}$ \\ ${ }^{a}$ Department Single Cell and Single Molecule Techniques, Institute of Molecular Biotechnology e.V., \\ P.O. Box 100813, D-07708 Jena, Germany \\ ${ }^{\mathrm{b}}$ Institute for Medical Physics and Laser Medicine, Free University Berlin, University Hospital Benjamin Franklin, \\ Fabeckstr. 60-62, D-14195 Berlin, Germany \\ ${ }^{\mathrm{c}}$ Present address: Kirchhoff-Institute of Physics, University of Heidelberg, Albert-Ueberle-Str. 3-5, D-69120 \\ Heidelberg, Germany
}

Received 12 November 2001

Accepted 4 June 2002

\begin{abstract}
The response of single breast cancer cells (cell line T-47D) to $17 \beta$-estradiol $\left(\mathrm{E}_{2}\right)$ under different concentrations was studied by using an instrument that allows to combine far-field light microscopy with high resolution scanning near-field (AFM/SNOM) microscopy on the same cell. Different concentrations of $E_{2}$ induce clearly different effects as well on cellular shape (in classical bright-field imaging) as on surface topography (atomic force imaging) and absorbance (near-field light transmission imaging). The differences range from a polygonal shape at zero via a roughly spherical shape at physiological up to a spindle-like shape at un-physiologically high concentrations. The surface topography of untreated control cells was found to be regular and smooth with small overall height modulations. At physiological $\mathrm{E}_{2}$ concentrations the surfaces became increasingly jagged as detected by an increase in membrane height. After application of the un-physiological high $\mathrm{E}_{2}$ concentration the cell surface structures appeared to be smoother again with an irregular fine structure. The general behaviour of dose dependent differences was also found in the near-field light transmission images. In order to quantify the treatment effects, line scans through the normalised topography images were drawn and a rate of co-localisation between high topography and high transmission areas was calculated. The cell biological aspects of these observations are, so far, not studied in detail but measurements on single cells offer new perspectives to be empirically used in diagnosis and therapy control of breast cancers.
\end{abstract}

Keywords: Light microscopy, scanning near-field optical microscopy (SNOM), transmission light SNOM, breast cancer cells, cell surface response, estrogen (17 $\beta$-estradiol) treatment

\section{Introduction}

Light microscopy is one of the most important inventions of man offering an insight into the $m i$ -

\footnotetext{
${ }^{*}$ Corresponding author: Dr. B. Perner, Institute of Molecular Biotechnology e.V., P.O. Box 100813, D-07708 Jena, Germany. Tel.: +49 3641 656405; Fax: +49 3641 656410; E-mail: perner@imbjena.de.
}

cro-cosmos of life. For instance, bright-field, phasecontrast, or fluorescence light microscopes are routinely applied instruments in medical research and diagnostics. These instruments belong to the so-called "far-field" microscopic techniques, which means that a propagating light wave illuminates the sample and a propagating light wave modulated by the object is recorded by eye or the detector system. Compared to the dimensions of the object the distances between 
light source, sample, and detector are large.

Despite the great benefit such high resolution, modern light microscopes have brought into life sciences, the nowadays commercially available instruments show principle short-comings especially for nano-structure investigations. Diffraction and other non-ideal optical conditions of biological specimens like variations of the refraction index limit the spatial resolution of a far-field light microscope [51,53] in practice to about $250 \mathrm{~nm}$ or even worse [15,28]. A general approach to overcome this limitation in fluorescence far-field microscopy is spectral precision distance microscopy [10], a technique that has been successfully applied in cytogenetics (e.g., [17]). This technique, however, does not image structural contrast modulation and limits the attainable information to objects labelled by fluorochromes.

The challenge to break the diffraction limit in resolution has led to the development of several novel imaging techniques, the so-called "near-field" techniques, which close the resolution gap between farfield light microscopy and electron microscopy in the visualisation of nano-structures. These near-field techniques use short distance interactions (typically in the range of molecular dimensions) between the sample and a scanning tip as parameters for imaging. The most prominent near-field technique in biological and medical applications is Atomic Force Microscopy (AFM), in which an atomically sharp probe attached to a cantilever is scanned over a sample surface. AFM has made nano-metre resolution also attainable in cell biology (e.g., [30]). However, although AFM produces a high-resolution topographical picture of the sample, it lacks specificity measurable by light absorption or fluorescence.

A combination of super-resolution optical microscopy and atomic force microscopy is therefore realised in another scanning probe technique: Scanning Near-Field Optical Microscopy (SNOM) [3,46, 61] which has been successfully applied to nanostructure analysis in solid state physics (e.g., [27,60]) and is going to become also a useful instrumental technology in life sciences (for review see e.g., [12]). As in AFM, a sharp probe scans the surface of the sample to obtain a topographic image. In addition, a laser beam is coupled into the probe tip for instance by means of an optical fibre. The most generally applied probes for biological specimen have an aperture with a diameter less than $100 \mathrm{~nm}$ which is much smaller than the wavelength of the laser light. This aperture acts as a pointlike light source that due to its size and shape emits predominantly evanescent waves and not, as a far-field light source, propagating waves. The intensity of these evanescent waves decreases exponentially in a range of some ten nano-metres around the probe tip so that the evanescent photons can only considerably contribute to sample illumination if the tip is close to the sample surface, i.e., in the range of molecular distances (typically in the order of about $10 \mathrm{~nm}$ ). In principle, a SNOM probe can be compared with a head-phone in acoustics whereas a standard light source in far-field microscopy works like a loud-speaker emitting a long range propagating sound wave.

Due to the size of the SNOM probe only a region of the sample less than $100 \mathrm{~nm}$ can be illuminated and only fluorophores in such a region can be excited to fluoresce. The transmitted light or sample fluorescence can be subsequently detected by a conventional farfield optics and transformed into an optical image that can be acquired simultaneously with the topographic (AFM) image. The spatial resolution of SNOM is approximately given by the aperture size and not by the wavelength of the illuminating light [4]. As in far-field light microscopy, the optical conditions of the sample influence the attainable resolution in practice. Biological objects are soft samples and three dimensionally extended with large height modulations (typically in the range of some $\mu \mathrm{m}$ ). These height modulations can limit the scan rate [57] and might cause interpretation problems since a strong coupling between topographic and optical imaging is not always preserved [2,21,25]. Recent estimates [4], however, have shown that also for biological samples near-field light microscopy with a spatial resolution in the sub-hundred nano-metre range becomes feasible.

SNOM imaging of biological objects has been shown for instance for cellular surfaces of fibroblasts, white blood cells, red blood cells, cytoskeletal actin, green fluorescent protein in bacteria, cortical neurons, or mitotic and meiotic chromosomes [1,16,20,31,34, $35,38,39,45,54,59]$. These applications show the principle advantages of using SNOM to study biological systems:

- The topographic nano-structure of the surface of the object together with specific optical information can be visualised with sub-hundred nm resolution.

- Optical and non-optical parameters can be acquired simultaneously and correlated quantitatively. 
- The near-field scanning unit can be adapted to a standard far-field microscope allowing near-field and far-field imaging under identical specimen conditions.

Although SNOM instruments optimised for biological investigations do not require special sample carriers and can be run with preparations on glass slides as in far-field microscopy, some constraints have to be considered in routine experiments. Since the SNOM tip to sample distance control is more critical to implement in a liquid environment than in air [12,29], the requirement for dry specimens is still state of the art, although promising approaches exist for SNOM in fluids [40]. Nevertheless good results were obtained by easy to handle structure conserving drying procedures as short time exposure to HMDS (see also Section 3: Cell preparation) [45].

It is well established that estrogens exhibit a large variety of functions in different cell-types, but the mechanisms of the estrogenic pathways are not yet fully understood $[7,8,11,33]$. The impact of environmental estrogenic contaminants on human and wildlife health is also discussed in scientific literature e.g., $[24,32,47,49,58]$. Estrogens induce rearrangements of cytoskeleton associated components in breast cancer cells resulting in alterations of cell morphologies and membrane structures $[9,13,14,50,52]$. For the investigations presented here, cells of the breast cancer cell line T-47D were bio-chemically modulated with the natural estrogen $17 \beta$-estradiol $\left(\mathrm{E}_{2}\right)$. This well established cell line was derived from the pleural effusion of a patient with disseminated carcinoma of breast [26]. T-47D cells contain estrogen and progesteron receptor proteins $[18,26]$.

The goal of this contribution is to show that SNOM has been developed to such a sophisticated technique that has the potential towards diagnostics on a single cell level. For the first time systematic SNOM analyses on breast cancer cells were made in order to study cellular response of estrogen accumulation expressed by cellular surface alterations. The SNOM unit was implemented into a standard far-field light microscope so that far-field images showing the shape of entire cells were acquired together with near-field topographic and transmission light images of pre-selected cell surface sections in the $\mu \mathrm{m}$-range.

\section{Instrumentation and image analysis}

SNOM images were acquired using a SNOM 210 (Fig. 1a) in the $\beta$-type state with standard instrumen- tation equipment (Carl Zeiss Jena $\mathrm{GmbH}$ ). The piezo scanning unit was integrated into the microscope condenser (Fig. 1b) of an Axiovert 135 microscope [20]. This allowed far-field and near-field imaging with the same instrument without changing the sample, i.e., both, far-field and near-field image acquisition modes, were performed on the same cell. In addition, the advantage of using standard glass slides allowed cell culture, growth and analysis on the same slides in order to minimise the preparation steps.

In order to correlate the whole cellular shape with the near-field image and to pre-select appropriate single cells for the near-field analysis, bright-field images were recorded using a CCD camera and a frame grabber board (Scion-Corporation). Image recording was controlled by the Scion Image 4.0 software running under Windows on a PC.

For SNOM, micro-fabricated SNOM-probes with silicon nitride tips coated with aluminium were mounted in a shear-force sensor support. The tips had an aperture of $\leq 100 \mathrm{~nm}$ as specified by the manufacturer (Institut für Mikrotechnik, Mainz). Typically the SNOM tip was used for about 10 hours scan-time until destruction of the aperture by laser exposure became visible. The instrument was equipped with an argon ion laser $(C=458 \mathrm{~nm}, 488 \mathrm{~nm})$ and two HeNe lasers $(C=543 \mathrm{~nm}, 633 \mathrm{~nm})$ for near field illumination. For each laser wavelength, the illumination intensity was tuned by an AOTF (Acousto Optical Tuneable Filter) independently. The laser light was coupled into the SNOM tip by glass fibres.

The topographic scan was controlled by measuring the interaction on the lateral shear-force oscillation (piezo bimorph excitation typically at about $70 \mathrm{kHz}$ ) of the SNOM probe. This limited the application to dry specimens only. Light absorption in the near-field range was detected in air through the glass slide by an Achroplan long distance objective $40 \times$ /NA 0.6 korr. and transferred to a photo-multiplier using appropriate band-pass filter settings (Zeiss Filter No. 15 and 16).

The instrument is controlled by the NanoScope IIIa (Digital Instruments Vecco $\mathrm{GmbH}$ ) controller. The scans were performed on sections of cell surfaces after far-field pre-selection. The scan velocity of the SNOM probe was less than $1 \mu \mathrm{m} / \mathrm{s}$ for typical image sizes of $2 \times 2 \mu \mathrm{m}^{2}$. All near-field images were recorded and visualised in three dimensional topographic false colour plots using the NanoScope IIIa software (version 4.42r1) running under Windows on a PC.

In order to analyse the cell surface height modulation of the differently treated samples by line scan rou- 


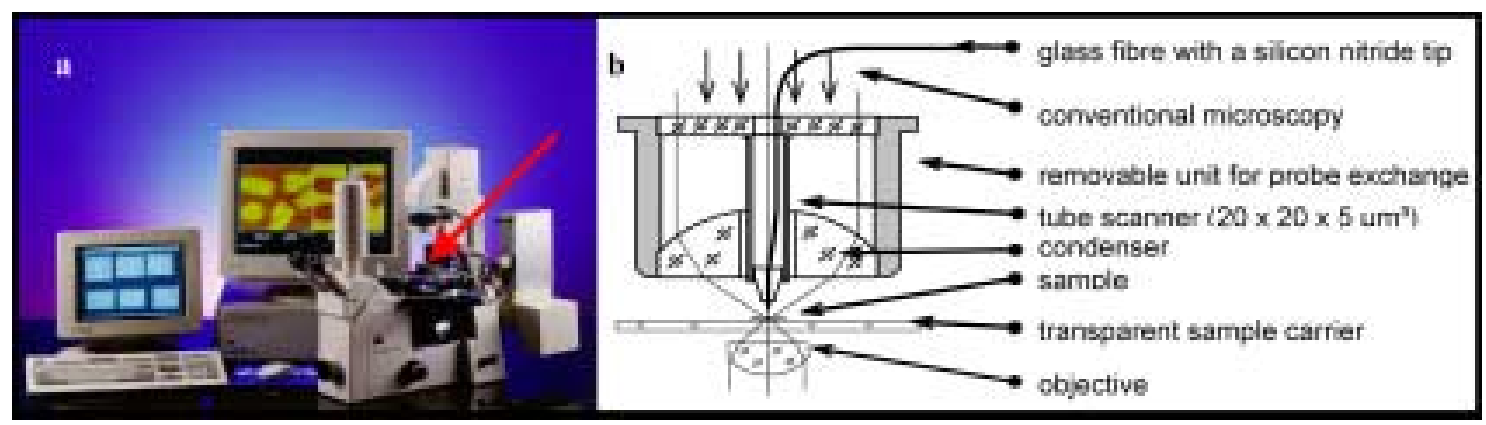

Fig. 1. (a) Setup of SNOM 210 based on an inverted far-field microscope. The arrow points at the condenser holding, the SNOM scan unit, and fibre probe schematically described in (b). (b) Schematic representation of the condenser and the integrated SNOM scan unit. (First published in Hausmann et al., Microscopy and Analysis 71 (May 2001), 5-7.)

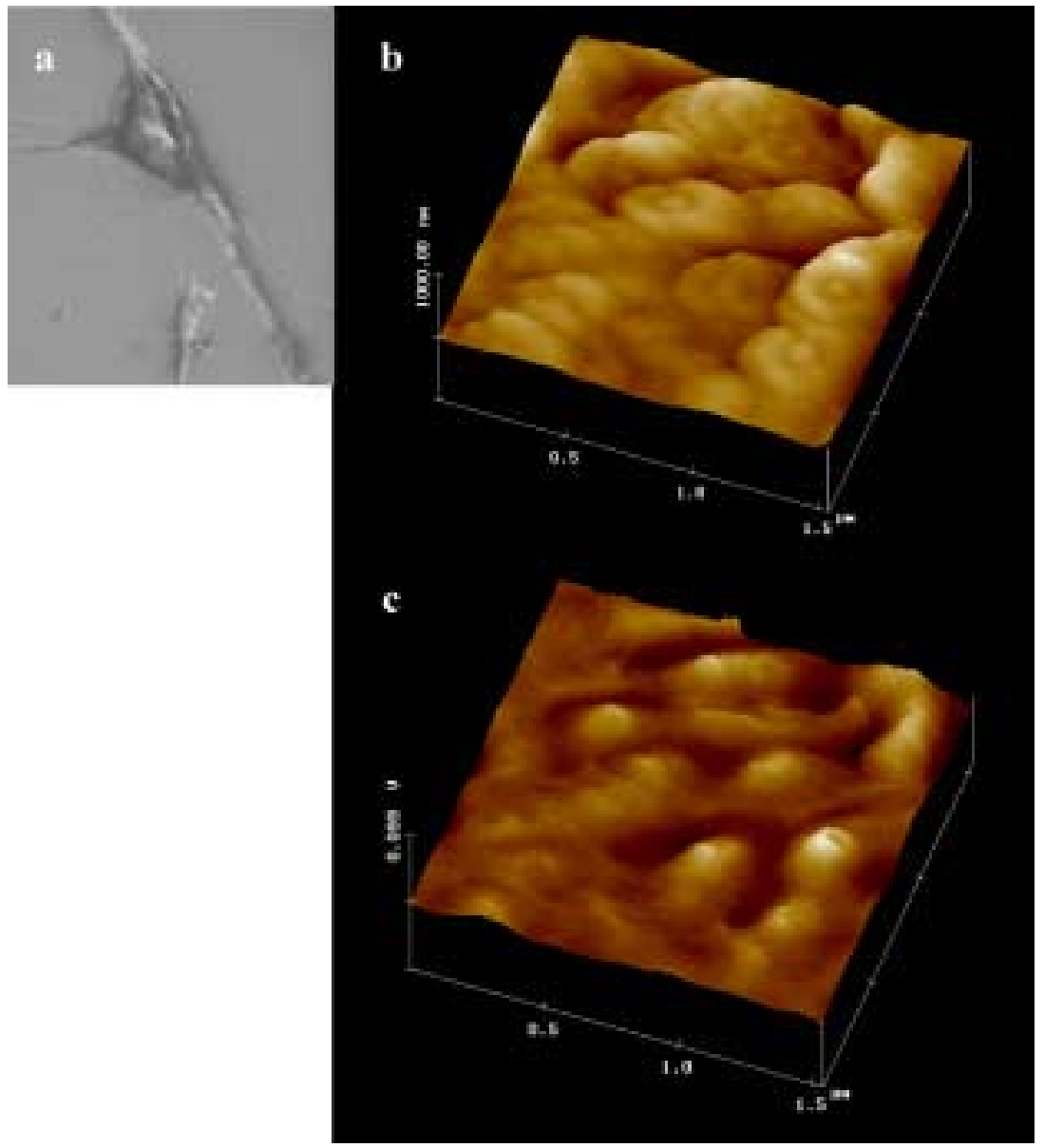

Fig. 2. (a) Far-field image of a cell of the breast cancer cell line T-47D (control without $E_{2}$ treatment) detected with $40 \times$ magnification; the typical polygonal shape is visible. (b) Near-field topographic image of a cellular surface section of the same breast cancer cell showing typical rosettes; (c) near-field transmission light image of the same surface section. Regions of the rosettes correspond to low absorbance regions. 
tines, the compared topographic images were re-scaled to identical ordinates by means of the Nanoscope software. Then the images were exported and further analysed using the Zeiss LSM software version 2.0.4. A diagonal line scan averaged over a width of five pixels was performed and plotted after normalisation of the abscissas of the exported images. The corresponding topographic and transmission images recorded simultaneously were analysed for a correlation between topographic height and surface absorbance ("surface quality factor"). For this purpose a programme was written under Scion Image 4.02 beta (Scion Corporation) on a Windows PC. Height and transmission images were normalised to maximum and minimum values by the Nanoscope software. These normalised images were subtracted pixel by pixel (relative topography - relative transmission = "surface quality"). This means for instance that high topographic values in combination to high transmission (= low absorbance) led to low differential values or low surface quality factors, respectively. A high topography in combination with low transmission (= high absorbance) led to a high surface quality factor. For graphic visualisation the resulting pixel values of the surface quality factor were divided by two and 128 arbitrary units were added. Thus, the results ranged from 0 to 255 which was represented by a histogram of 50 classes, where at 128 the lowest surface quality factor was found. By these histograms, images with a close correlation of topographic height and high transmission were represented by a distribution of a small width.

\section{Cell preparation}

Breast cancer cells of the cell line T-47D (ATCC HTB 133) were grown on chambered glass slides (Nalge Nunc International, Naperville, USA) and cultivated in RPMI 1640 cell culture medium with $10 \%$ fetal calf serum at $37^{\circ} \mathrm{C}$ with $5 \% \mathrm{CO}_{2}$ in a humidified atmosphere. 3-4 days before reaching a confluent cell monolayer the medium was changed to phenol red free RPMI 1640 including 5\% charcoal-stripped [9] fetal calf serum, 1\% antibiotic/antimycotic solution (GIBCO BRL Life Technologies), $2 \mathrm{mM}$ glutamine, and $1 \%$ non-essential amino acids solution. The medium was tested to be free from residual estrogens and components with estrogen like activities. If not stated otherwise all cell culture media and supplements were purchased from Biochrom KG Seromed, Berlin, Germany.
After 6 days of further cultivation aliquots of the cells were treated for 48 hours with $17 \beta$-estradiol $\left(\mathrm{E}_{2}\right)$ (Sigma-Aldrich Chemie GmbH, Deisenhofen, Germany) at concentrations of $5 \times 10^{-9} \mathrm{M}, 5 \times 10^{-7} \mathrm{M}$, or $5 \times 10^{-5} \mathrm{M}$. The $\mathrm{E}_{2}$ stock solution was prepared in ethanol. For microscopy the cell culture medium was removed and the cells were washed twice in PBS (30 min each). Then the cells were fixed with $4 \%$ formaldehyde in PBS for $15 \mathrm{~min}$ (room temperature), washed again in PBS for $15 \mathrm{~min}$ and dehydrated by an ethanol series $(70 \%, 80 \%, 90 \%, 100 \%)$ for $5 \mathrm{~min}$ each. In order to maintain cellular structures, air-drying of the specimen was performed after hexamethyldisilazane (HMDS) exposure for $3 \mathrm{~min}$ [45] because HMDS was known to reduce surface tension and to induce cross-linking in proteins.

\section{Results}

Cells were cultivated directly on chambered glass slides in $0.8 \mathrm{ml}$ medium per sample ensuring parallel preparation and detection conditions for all different aliquots. Bright field images were recorded at a $40 \times$ magnification. 15-20 cells were selected and imaged for each $\mathrm{E}_{2}$ concentration and the non-treated control. A dose-dependent $\mathrm{E}_{2}$ stimulation of T-47D cell proliferation was observed: After application of $5 \times 10^{-9} \mathrm{M}$ and $5 \times 10^{-7} \mathrm{M} \mathrm{E}_{2}$ more cells with a higher degree of confluence were found on the glass slides. For $E_{2}$ treatment with the highest concentration $\left(5 \times 10^{-5} \mathrm{M}\right)$ the cell density was decreased in comparison to the untreated control.

As a selection criterion for SNOM, single cells spatially separated from the confluent cell colony were taken for image acquisition. In these cases the cells showed a typical treatment dependent single cell shape. From these pre-selected cells, surface sections were selected for SNOM imaging. A topographic image and a near-field light transmission image at $488 \mathrm{~nm}$ were acquired simultaneously.

In Fig. 2, a typical example of an untreated control cell is shown. The far-field image (Fig. 2a) revealed a typically flat, epitheloid cell of polygonal shape. In the topographical near-field image (Fig. 2b) typical rosette like structures were visible. The surface appeared to be regular and the overall height modulations over a $\mu$ m-dimensional surface region were small (Fig. 6). In the near-field transmission image (Fig. 2c) the areas of low absorbance corresponded to the rosettes in the topographical image. 


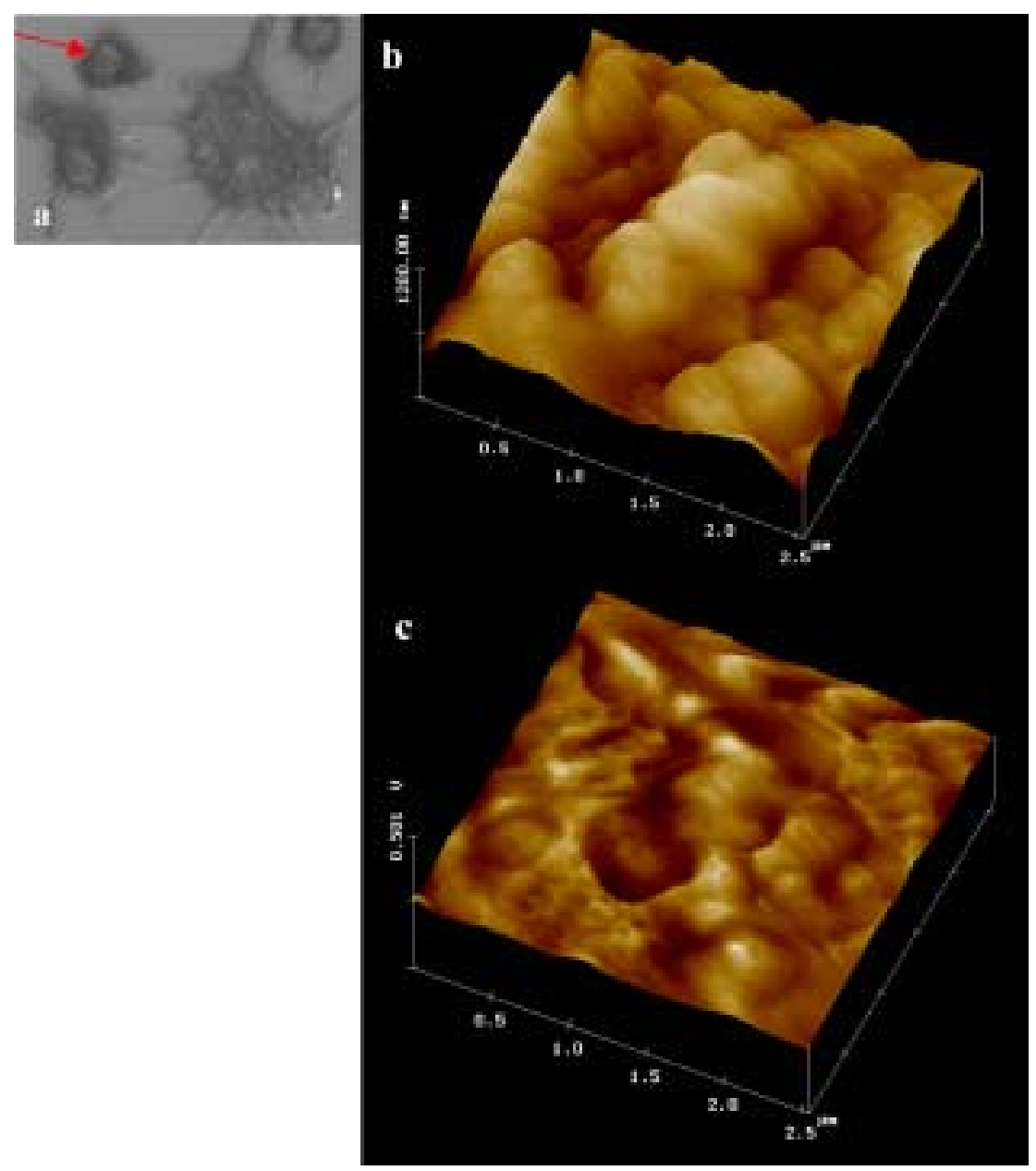

Fig. 3. (a) Far-field image of cells of the breast cancer cell line T-47D (after 48 hours treatment with $5 \times 10^{-9} \mathrm{M} \mathrm{E}_{2}$ ) detected with $40 \times$ magnification; typical globular shape is visible. (b) Near-field topographic image of a cellular surface section of the breast cancer cell indicated in (a) by an arrow; typical rosettes separated by furrows are visible; (c) near-field transmission light image of the same surface section. Regions of the rosettes do not always correspond to low absorbance regions.

In contrast to Fig. 2, the cellular appearance changed with $\mathrm{E}_{2}$ treatment. After application of $5 \times 10^{-9} \mathrm{M} \mathrm{E}_{2}$ (Fig. 3) the polygonal shape disappeared and globular cells were typically found (Fig. 3a). In the topographic image (Fig. 3b) the rosettes were higher and some were more pronounced due to separation by elongated furrows. In these furrows flat rosettes were detected. A correlation to low absorbance regions was only found for a few rosettes but not for all (Fig. 3c).

The latter effect was also detected for $5 \times 10^{-7} \mathrm{M} \mathrm{E}_{2}$ (Fig. 4c). In this case the topographic images revealed strongly furrowed surfaces with less rosettes (Fig. 4b) accompanied by an increased globularity of the cell shape as detected in the bright-field image (Fig. 4a)

Globularity, furrowed surfaces, and an increased absorbance in the rosettes could be assigned to an $\mathrm{E}_{2}$ treatment under physiological concentrations. This behaviour was completely different for the un-physiological concentration of $5 \times 10^{-5} \mathrm{M} \mathrm{E}_{2}$. Under this condition the cells appeared spindle-like shaped in the bright-field (Fig. 5a). Again the cellular surface was flat but only a few, intimated rosettes were visible in the topographic image (Fig. 5b). Moreover, the optical response of the surface expressed by the light transmission image (Fig. 5c) was neither compatible to the control nor to the low dose $\mathrm{E}_{2}$ treatment. Nearly no correlation between high or low absorbance areas and the remaining uncomplete rosettes were found (Fig. 7).

To quantify the high modulation of the cells treated with different concentrations of $E_{2}$ line scans along the normalised diagonals of the images were measured. In Fig. 6 they are plotted for the four typical exam- 


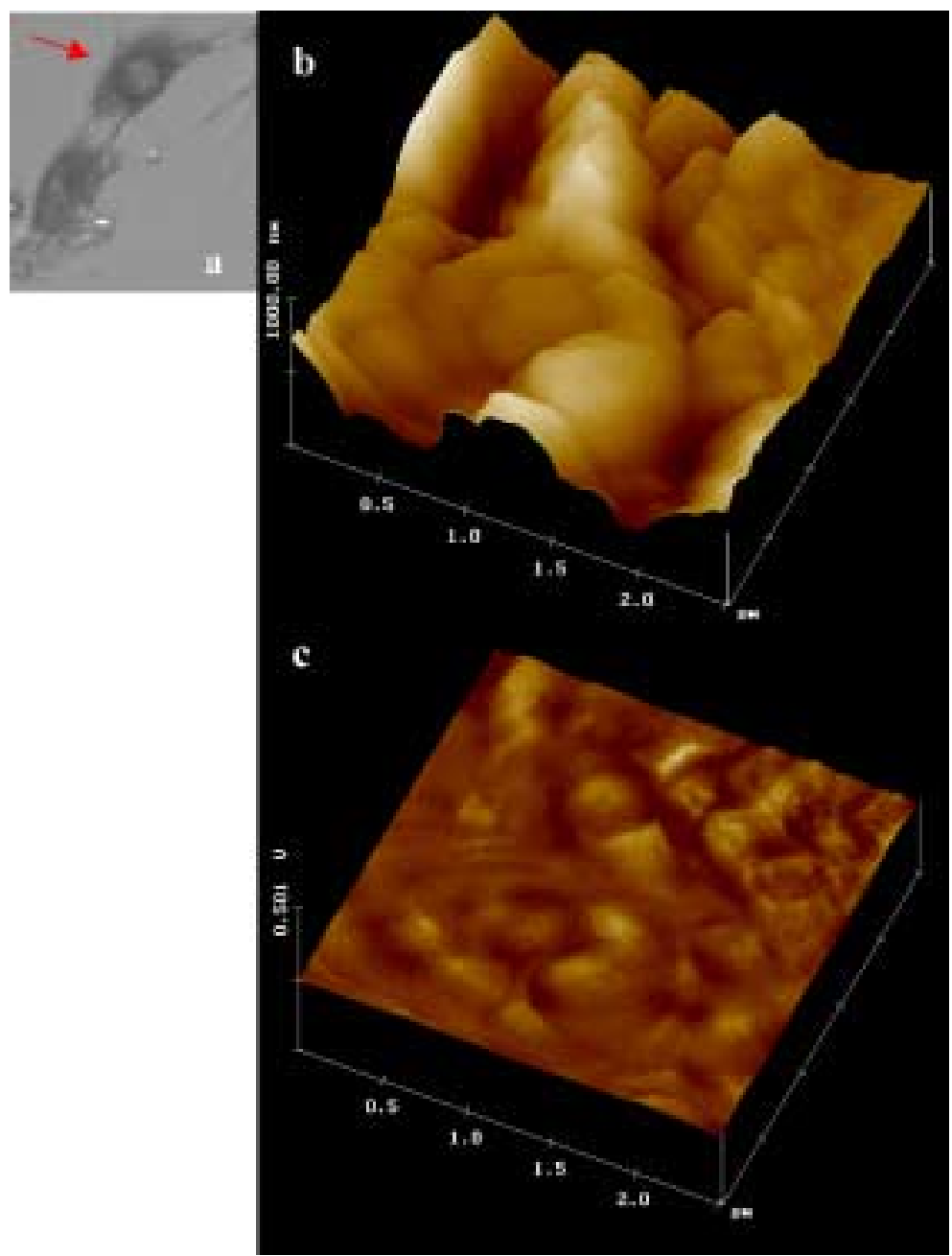

Fig. 4. (a) Far-field image of cells of the breast cancer cell line T-47D (after 48 hours treatment with $5 \times 10^{-7} \mathrm{M} \mathrm{E}_{2}$ ) detected with $40 \times$ magnification; typical globular shape is visible. (b) Near-field topographic image of a cellular surface section of the breast cancer cell indicated in (a) by an arrow; strong furrows with a few rosettes only are visible; (c) near-field transmission light image of the same surface section. Regions of the rosettes do not always correspond to low absorbance regions.

ples shown in Figs 2-5. A dose dependent increase in high modulations and membrane ruffling occurred in the range from 0 to $5 \times 10^{-7} \mathrm{M} \mathrm{E}_{2}$. Increasing the $\mathrm{E}_{2}$ concentration to $5 \times 10^{-5} \mathrm{M}$ the membrane structure was completely flattened.

In Fig. 7 the histograms of the surface quality factors are shown for the examples of Figs 2-5. A high rate of co-localisation between high topography and high transmission (corresponding to a small histogram width of about 128) was found for the untreated control. In this case the rosettes were the regions of high transmission. The treatment of the cells with physio$\operatorname{logical} \mathrm{E}_{2}$ concentrations $\left(5 \times 10^{-9}-5 \times 10^{-7} \mathrm{M}\right)$ induced a clearly decrease of the correlation (visible as a broader histogram). At un-physiological high concen- trations nearly no co-localisation was found between membrane height and transmission.

\section{Discussion and conclusion}

Human breast cancer cells maintained in long term culture containing estrogen and progesteron receptors constitute a good experimental model for studying hormon-tumour interaction. The cell lines are diverse in their origin and their responsiveness to cytochemical treatments [55]. Signal transduction and regulatory pathways induce cellular modifications to its environmental status (e.g., the estradiol concentration). This 


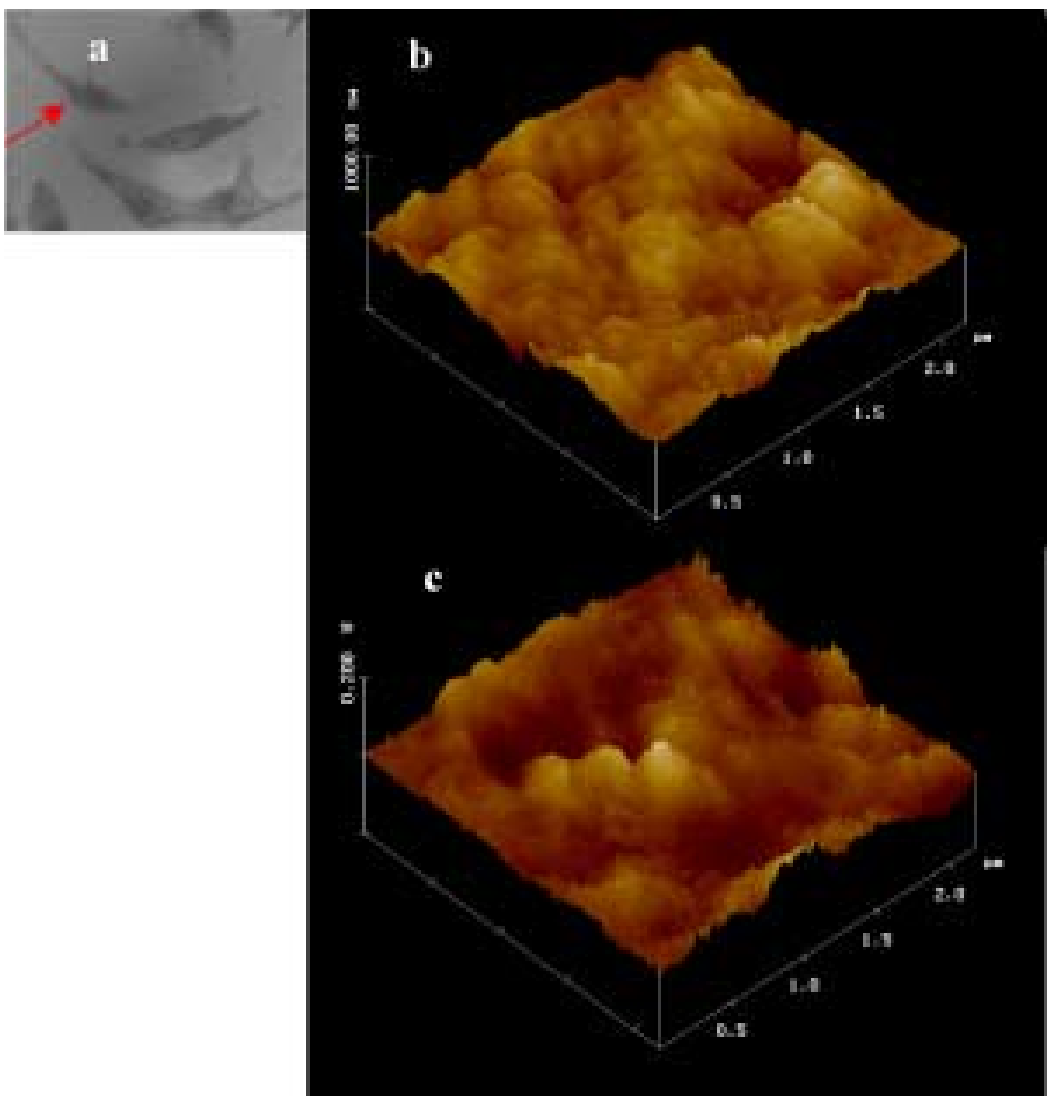

Fig. 5. (a) Far-field image of cells of the breast cancer cell line T-47D (after 48 hours treatment with $5 \times 10^{-5} \mathrm{M} \mathrm{E}_{2}$ ) detected with $40 \times$ magnification; typical spindle like shape is visible. (b) Near-field topographic image of a cellular surface section of the breast cancer cell indicated in (a) by an arrow; only intimated rosettes are visible; (c) near-field transmission light image of the same surface section. Regions of the rosettes do not correspond to low absorbance regions.

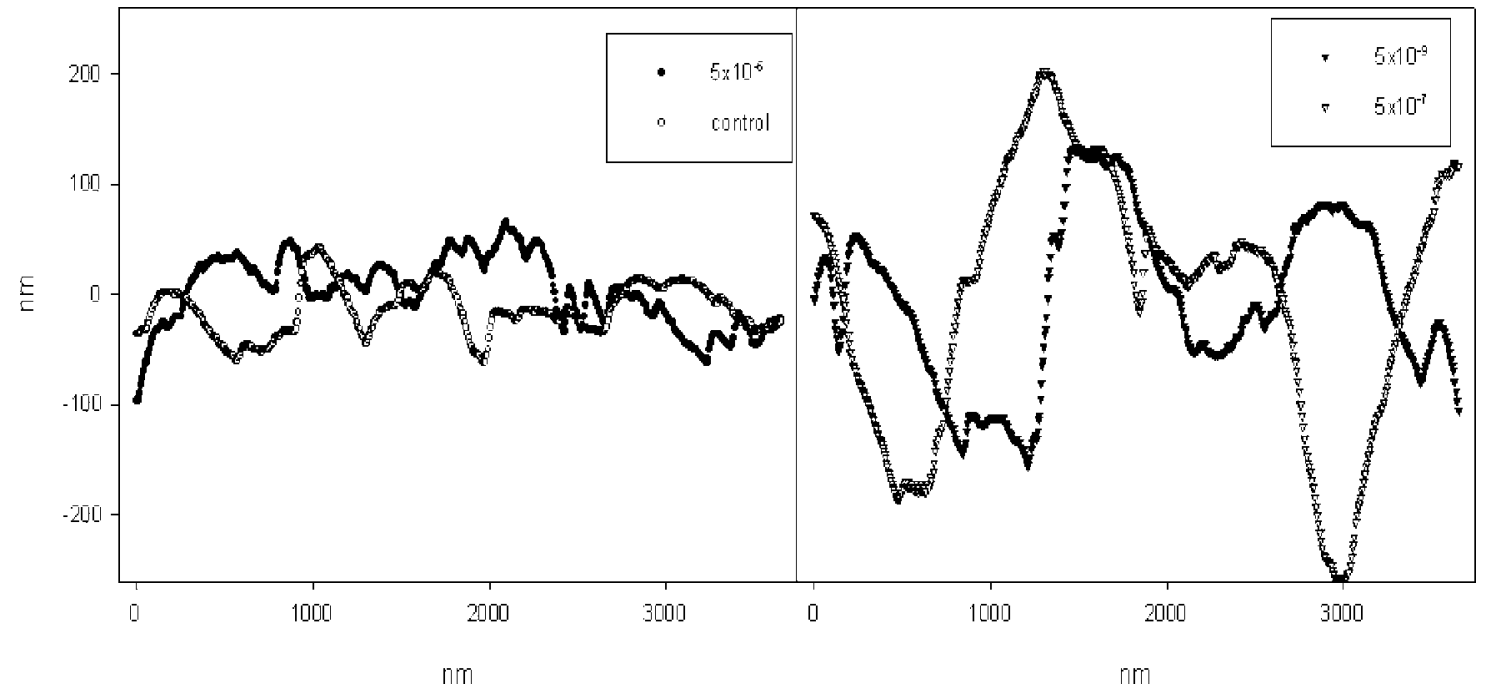

Fig. 6. Line scans along the diagonal of the normalised topographic images. In comparison to the untreated control the height modulation increased with the $\mathrm{E}_{2}$ concentration from $5 \times 10^{-9} \mathrm{M}$ to $5 \times 10^{-7} \mathrm{M}$. With a further increase to $5 \times 10^{-5} \mathrm{M}$ the cytotoxic effect becomes visible with flattening of the membrane topology. 


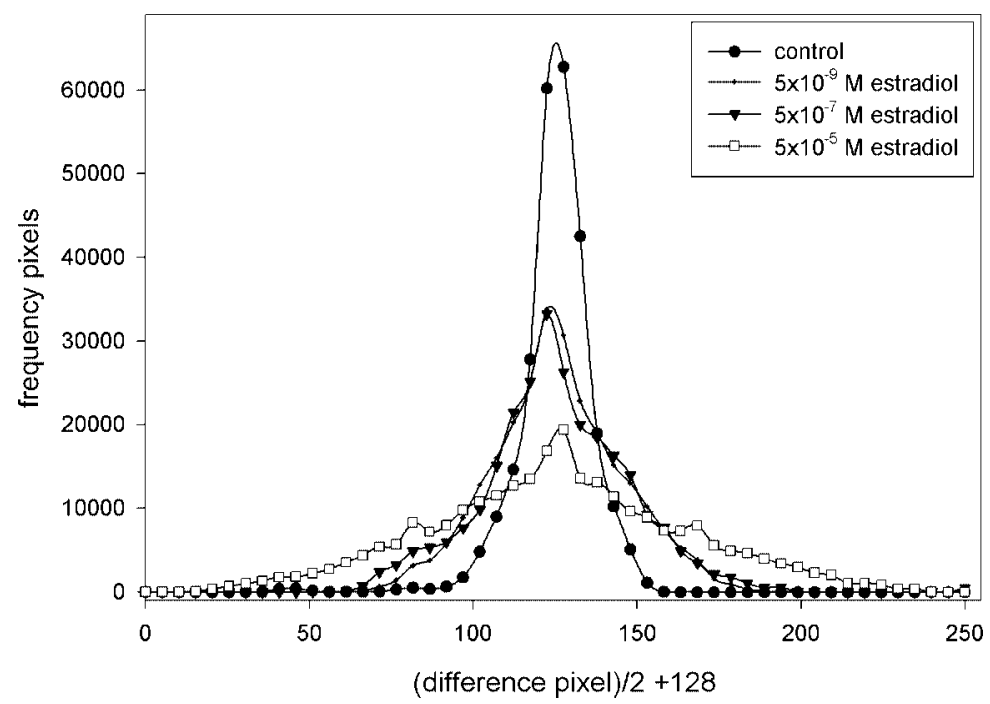

Fig. 7. Histogram of the surface quality factors describing the pixel by pixel co-localisation between topographic height and transmission. The factors were calculated from the corresponding images (for details see section 2: Instrumentation and image analysis). The value of 128 represents an optimum co-localisation.

can be detected in detail by controlling the level of expression of genes with molecular techniques, e.g., [44]. Since such molecular mechanisms should influence the supra-molecular appearance of cell surfaces we tried to establish surface portraits of single human breast cancer cells by SNOM in correlation to bright-field imaging of the whole cell. The results indicate that $\mathrm{E}_{2}$ treatment of different concentrations can be visualised on the single cell level by typical structures detected by means of SNOM. To quantify such effects, the surface quality factors correlating near-field topography with near-field light transmission can be used as a reasonable measure for treatment response.

Although [22] have reported that T-47D cell growth was not influenced by both, estrogens and anti-estrogens, several studies revealed a clear estrogen stimulation of proliferation. This ranged from a 2-fold to a 13-fold increase of cells as assessed by cell counting $[19,23]$, evaluation of cellular DNA $[5,6,18,56]$ or measuring of ${ }^{3} \mathrm{H}$ thymidine [6]. On the other hand it has been shown that this stimulation is inhibited by anti-estrogens $[18,19,48,56]$. Depending on the special experimental conditions a very different degree of responsiveness of the T-47D cells was found. A proliferating effect of estrogen was also found for an other well established breast cancer cell line named MCF-7 $[36,42,43]$.

Since we worked with fixed, air dried specimen, we did not make such proliferation measurements in correlation to our single cell SNOM results. However, our findings in general agree with the fact that $\mathrm{E}_{2}$ has a mitogenic effect. We observed a dose-dependent T-47D cell proliferation by inspection of the cell confluence in comparison to the untreated control. These observations agree in principle with [56] in which a cytotoxic effect of $E_{2}$ on T47-D at concentrations above $10^{-6} \mathrm{M}$ has been described. A biphasic effect but with maximal growth stimulation at $10^{-9} \mathrm{M}$ was found by [6]. The differences may depend on similar factors as described for the variation in estradiol responsiveness.

In this report we have concentrated on the practicability of SNOM for systematic studies. The use of a commercial standard far-field microscope with an implemented SNOM unit brought this technique into a routine laboratory of cell biology. The combination of far-field and near-field imaging in one instrument under identical specimen conditions allowed the detection of micro structures and sub-hundred nano-metre, supra-molecular structures of the same cell.

Although the $z$-range for our scan head was only $1.7 \mu \mathrm{m}$ which was rather small for scanning on surfaces of intact cells, this limited $z$-range was high enough, if accurate positioning and landing of the SNOM tip on the pre-selected surface section was achieved. However, it should be mentioned that this was time consuming and not always easy to handle. A scan head with a $z$-range of $5 \mu \mathrm{m}$ which is meanwhile available would reduce this shortcoming.

Nevertheless, series of cells could be acquired and the typical modifications in the cellular shape and sur- 
face morphology were extracted. In comparison with the polygonal shapes and regular topologies of control cells the $\mathrm{E}_{2}$ treated cells exhibited dose-dependant alterations concerning morphologies and topographic patterns. The cellular membrane appeared to be destroyed by toxicity of the un-physiological high $\mathrm{E}_{2}$ concentration, since structural sub-units like rosettes disappeared in an un-structured flat surface. The subtoxic concentrations $\left(5 \times 10^{-9}-5 \times 10^{-7} \mathrm{M}\right)$, however, showed an increase in membrane height which might correspond to cell activity and proliferation. Obvious morphological changes (more elongated and spindle shaped cells) observed by far-field microscopy were also found for human endothelial cells after stimulation of proliferation by an infection with two Bartonella species. This infection is associated with proliferative neovascular lesions [41].

The specimen drying procedure using ethanol dehydration and HMDS treatment [45] was well manageable and had no apparent destructive influence on the cellular shape or surface. However, working with dry samples seems to be still the most difficult shortcoming of SNOM for biological research. It might limit a general application as a high resolution optical technique breaking the diffraction limit. In addition, working in air reduces the photo-stability of many fluorochromes which are applied in modern biology for specific labelling of cells and sub-cellular components. The challenge of future developments will be to overcome these shortcomings of SNOM for biological analyses [12].

Here, we did not use fluorescent labels and analysed the native absorbance of the specimen. Using three dimensionally intact cells the question is, whether the near-field transmission signal was readily contrasted by the surface of the cell. In far-field imaging the illumination light is passing the whole cell and therefore the detected image is an integrated signal across the entire cell thickness. Due to the exponential attenuation of the illumination light away from the nearfield aperture, the near-field transmission light image is mostly contrasted from the few ten nanometres thick layer close to the surface and therefore represents the optical density of the membrane. The chosen image sections for SNOM were small compared to highly absorbing organelles in the cell like for instance a nucleus. Thus, it can be concluded that detailed structures in the transmission light image can only be registered if the absorbance of the cytoplasm can be assumed to be homogenous and therefore negligible.

We acknowledge that so far our results are only descriptive and lack a functional correlation. However, we believe that in future a detailed knowledge about cellular mechanisms like protein induced membrane ruffling [37] and it's modulation by chemical treatment might explain typical cell surface portraits. Our experiments, therefore, may methologically be seen as a first study to investigate cellular responsiveness by a single cell technique. The observations may also offer perspectives to be empirically used in diagnosis and therapy control of breast cancers.

\section{Acknowledgement}

Funding of the BMBF (Bundesminister für Bildung und Forschung) and the instrumental support by Carl Zeiss Jena $\mathrm{GmbH}$ are gratefully acknowledged. The authors also thank B. Lanick and G. Günther for technical assistance.

\section{References}

[1] W.P. Ambrose, R.L. Affleck, P.M. Goodwin, R.A. Keller, J.C. Martin, J.T. Petty, J.A. Schecker and M. Wu, Imaging of biological molecules with single molecule sensitivity using near-field scanning optical microscopy, Exp. Techn. Phys. 41 (1995), 237-248.

[2] D. Barchiesi, Characterization of reflection scanning nearfield optical microscopy and scanning tunneling optical microscopy/photon scanning tunneling microscopy working in preliminary approach constant height scanning mode, J. Microsc. 194 (1999), 299-306.

[3] E. Betzig, A. Lewis, A. Harootuniam, M. Isaacson and E. Kratschmer, Near-field scanning optical microscopy (NSOM): Development and biophysical applications, Biophys. J. 49 (1986), 269-279.

[4] J. Beuthan, M. Hausmann, O. Minet, B. Perner, C. Dressler and H.G. Eberle, Approximative determination of the modulation transfer function of the scanning near field microscope using biological samples. Techn. Messen 3/2001 (2001), 127-130.

[5] V. Cappelletti, P. Miodini, L. Fioravanti and G. Di Fronzo, Effect of progestin treatment on estradiol- and growth factorstimulated breast cancer cell lines, Anticancer Res. 15 (1995), 2551-2555.

[6] D. Chalbos, F. Vignon, I. Keydar and H. Rochefort, Estrogens stimulate cell proliferation and induce secretory proteins in a human breast cancer cell line $\left(\mathrm{T}_{47} \mathrm{D}\right)$, J. Clin. Endocrin. Metabol. 55 (1982), 276-283.

[7] T.-Y. Chun and J. Gorski, High concentrations of bisphenol A induce cell growth and prolactin secretion in estrogenresponsive pituitary tumor cell line, Toxicol. Appl. Pharmacol. 162 (2000), 161-165.

[8] T.-Y. Chun, D. Gregg, D.K. Sarkar and J. Gorski, Differential regulation by estrogens of growth and prolactin synthesis in pituitary cells suggests that only a small pool of estrogen receptors is required for growth, Proc. Natl. Acad. Sci. USA 95 (1998), 2325-2330. 
[9] A.S. Coutts, J.R. Davie, H. Dotzlaw and L.C. Murphy, Estrogen regulation of nuclear matrix-intermediate filament proteins in human breast cancer cells, J. Cell. Biochem. 63 (1996), 174184.

[10] C. Cremer, P. Edelmann, A. Esa, H. Bornfleth, B. Schneider, J. Bradl, B. Rinke, L. Trakhtenbrot, S. Dietzel, M. Hausmann and T. Cremer, Spektrale Präzisionsdistanzmikroskopie in der Genomforschung, Z. Med. Phys. 9 (1999), 14-20.

[11] K. Dechering, C. Boersma and S. Mosselman, Estrogen receptor alpha and beta: two receptors of a kind?, Curr. Med. Chem. 7 (2000), 561-576.

[12] F. de Lange, A. Cambi, R. Huijbens, B. de Bakker, W. Rensen, M. Garcia-Parajo, N. van Hulst and C.G. Figdor, Cell biology beyond the diffraction limit: near-field scanning optical microscopy, J. Cell Sci. 114 (2001) 4153-4160.

[13] J.A. DePasquale, Rearrangement of F-actin cytoskeletal in estradiol-treated MCF-7 breast carcinoma cells, Histochem. Cell Biol. 112 (1999), 341-350.

[14] J.A. DePasquale, W.A. Samsonoff and J.F. Gierthy, 17-betaestradiol induced alterations of cell-matrix and intercellular adhesions in human mammary carcinoma cell line, J. Cell Sci. 107 (1994), 1241-1254.

[15] P. Edelmann, A. Esa, M. Hausmann and C. Cremer, Confocal laser-scanning fluorescence microscopy: In situ determination of the confocal point-spread function and the chromatic shifts in intact cell nuclei, Optik 110 (1999), 194-198.

[16] T. Enderle, T. Ha, D.F. Ogletree, D.S. Chemla, C. Magowan and $\mathrm{S}$. Weiss, Membrane specific mapping and colocalization of malarial and host skeletal proteins in the Plasmodium falciparum infected erythrocyte by dual-color near-field scanning optical microsopy, Proc. Natl. Acad. Sci. USA 94 (1997), 520525.

[17] A. Esa, P. Edelmann, G. Kreth, L. Trakhtenbrot, N. Amariglio, G. Rechavi, M. Hausmann and C. Cremer, Three-dimensional spectral precision distance microscopy of chromatin nanostructures after triple-colour DNA labelling: a study of the BCR region on chromosome 22 and the Philadelphia chromosome, J. Microsc. 199 (2000), 96-105.

[18] P.G. Gill, W. Tilley, N.J. De Young, I.L. Lensink, P.D. Dixon and D.J. Horsfall, Inhibition of T-47D human breast cancer cell growth by the synthetic progestin R5020: effects of serum, estradiol, insulin, and EGF, Breast Cancer Res. Treat. 20 (1991), 53-62.

[19] M. Gupta, A. McDougal and S. Safe, Estrogenic and antiestrogenic activities of 16alpha- and 2-hydroxy metabolites of 17beta-estradiol in MCF-7 and T47D human breast cancer cells, J. Steroid Biochem. Mol. Biol. 67 (1998), 413-419.

[20] M. Hausmann, B. Perner, A. Rapp, H. Scherthan and K.O. Greulich, SNOM imaging of mitotic and meiotic chromosomes, Microsc. Analyt. 5/2001 (2001), 13-15.

[21] B. Hecht, H. Bielefeldt, Y. Inouye and D.W. Pohl, Facts and artifacts in near-field optical microscopy, J. Appl. Phys. 81 (1997), 2492-2498.

[22] K.B. Horwitz, M.B. Mockus and B.A. Lessey, Variant T47D human breast cancer cells with high progesterone-receptor levels despite estrogen and antiestrogen resistance, Cell $\mathbf{2 8}$ (1982), 633-642.
[23] K. Iwasaki, B. Underwood, M. Herman, S. Dinda, S. Kodali, H.J. Kloosterboer, C. Hurd and V.K. Moudgil, Effects of antiprogestins on the rate of proliferation of breast cancer cells, Mol. Cell Biochem. 198 (1999), 141-149.

[24] D.R. Juberg, An evaluation of endocrine modulators: implications for human health, Ecotox. Environ. Saf. 45 (2000), 93105.

[25] T. Kalkbrenner, M. Graf, C. Durkan, J. Mlynek and V. Sandoghdar, High-contrast topography-free sample for near-field optical microscopy, Appl. Phys. Lett. 76 (2000), 1206-1208.

[26] I. Keydar, I. Chen, S. Karby, F.R. Weiss, J. Delarea, M. Radu, S. Chaitcik and H.J. Brenner, Establishment and characterization of a cell line of human breast carcinoma origin, Europ. J. Cancer 15 (1979), 659-670.

[27] J. Koglin, U.C. Fischer and H. Fuchs, Material contrast in scanning near-field optical microscopy (SNOM) at $1-10 \mathrm{~nm}$ resolution, Phys. Rev. B 55 (1997), 7977-7984.

[28] M. Kozubek, Theoretical versus experimental resolution in optical microscopy, Microsc. Res. Techn. 53 (2001), 157-166.

[29] P. Lambelet, M. Pfeffer, A. Sayah and F. Marquis-Waible, Reduction of tip-sample interaction forces for scanning near-field optical microscopy in a liquid environment, Ultramicroscopy 71 (1998), 117-121

[30] P.P. Lehenkari, G.T. Charras, A. Nykanen and M.A. Horton, Adapting atomic force microscopy for cell biology, Ultramicroscopy 82 (2000), 289-295.

[31] A. Lewis, A. Radko, N.B. Ami, D. Palanker and K. Lieberman, Near-field scanning optical microscopy in cell biology, TICB 9 (1999), 70-73.

[32] J.G. Liehr, Is estradiol a genotoxic mutagenic carcinogen?, Endocr. Rev. 21 (2000), 40-54.

[33] J.I. Macgregor and V.C. Jordan, Basic guide to the mechanisms of antiestrogenic action, Pharmacol. Rev. 50 (1998), 151-196.

[34] A.J. Meixner and H. Kneppe, Scanning near-field optical microscopy in cell biology and microbiology, Cell. Mol. Biol. 44 (1998), 673-688.

[35] R. Micheletto, M. Denyer, M. Scholl, K. Nakajima, A. Offenhauser, M. Hara and W. Knoll, Observation of the dynamics of live cardiomyocytes through a free-running scanning near-field optical microscopy setup, Appl. Opt. 38 (1999), 6648-6652.

[36] M. Lippmann, G. Bolan and K. Huff, The effects of estrogens and antiestrogens on hormone-responsive human breast cancer in long-term tissue culture, Cancer Res. 36 (1976), 4595-4601.

[37] F. Michiels, G.G. Habets, J.C. Stam, R.A. van der Kammen and J.G. Collard, A role for Rac in Tiam1-induced membrane rufling and invasion, Nature 375 (1995), 338-340.

[38] M.H.P. Moers, W.H.J. Kalle, A.G.T. Ruiter, J.C.A.G. Wiegant, A.K. Raap, J. Greve, B.G. Degroth and N.F. van Hulst, Fluorescence in situ hybridization of human metaphase chromosomes detected by near-field scanning optical microscopy, J. Microsc. 182 (1996), 40-45.

[39] M.H.P. Moers, A.G.T. Ruiter, A. Jalocha and N.F. van Hulst, Detection of fluorescence in situ hybridization on human metaphase chromosomes by near-field scanning optical microscopy, Ultramicroscopy 61 (1995), 279-283.

[40] A. Naber, H.-J. Maas, K. Razavi and U.C. Fischer, Dynamic force distance control suited to various probes for scanning near-field optical microscopy, Rev. Sci. Instr. 70 (1999), 39553961. 
[41] J. Palmari, N. Teysseire, C. Dussert and D. Raoult, Image cytometry and topographical analysis of proliferation of endothelial cells in vitro during Bartonella (Rochalimaea) infection, Analyt. Cell. Pathol. 11 (1996), 13-30.

[42] J. Palmari, F. Wallet, J. Berard, Y. Berthois, P.M. Martin and C. Dussert, Morphological evidence for a subpopulation effect by estrogen and antiestrogen treatments in the heterogenous MCF-7 cell line, Analyt. Cell. Pathol. 20 (2000), 99-113.

[43] J.T. Papendorp, R.W. Schatz, A.N. Soto and C. Sonnenschein, On the role of 17 alpha-estradiol and 17 Beta-estradiol in the proliferation of MCF7 and T47D-A11 human breast tumor cells, J. Cell. Physiol. 125 (1985), 591-659.

[44] C.M. Perou, T. Soerlie, M.B. Eisen, M. van de Rijn, S.S. Jeffrey, C.A. Rees, J.R. Pollack, D.T. Ross, H. Johnsen, L.A. Aksien, O. Fluge, A. Pergamenschikov, C. Williams, S.X. Zhu, P.E. Loenning, A.-L. Boerresen-Dale, P.O. Brown and D. Botstein, Molecular portraits of human breast tumours, Nature 406 (2000), 747-752.

[45] B. Perner, M. Hausmann, L. Wollweber, A. Rapp, S. Monajembashi and K.O. Greulich, Scanning near-field optical microscopy of cell surfaces after structure conserving air-drying, Proc. SPIE 4164 (2000), 10-17.

[46] D.W. Pohl, W. Denk and M. Lanz, Optical stethoscopy: Image recording with resolution C/20, Appl. Phys. Lett. 44 (1984), 651-653.

[47] T. Rao and B. Richardson, Environmentally induced autoimmune diseases: potential mechanisms, Environ. Health Perspect. 107(Suppl. 5) (1999), 737-742.

[48] C. Ruedl, V. Cappelletti, D. Coradini, G. Granata and G. Di Fronzo, Influence of culture conditions on the estrogenic cell growth stimulation of human breast cancer cells, J. Steroid Biochem. Mol. Biol. 37 (1990), 195-200.

[49] S.H. Safe, Endocrine disruptors and human health - is there a problem? An update, Environ. Health Perspect. 108 (2000), 487-493.

[50] A. Sapino, F. Pietribiasi, G. Bussolanti and P.C. Marchisio, Estrogen- and tamoxifen-induced rearrangements of cytoskeletal adhesion structures in breast cancer MCF-7 cells, Cancer Res. 46 (1986), 2526-2531.
[51] M. Sarikaya, Evolution of resolution in microscopy, Ultramicroscopy 47 (1992), 1-14.

[52] V.A. Spencer, A.S. Coutts, S.K. Samuel, L.C. Murphy and J.R. Davie, Estrogen regulates the association of intermediate filament proteins with nuclear DNA in human breast cancer cells, J. Biol. Chem. 273 (1998), 29 093-29 097.

[53] E.H.K. Stelzer, Contrast, resolution, pixelation, dynamic range and signal-to-noise ratio: fundamental limits to resolution in fluorescence microscopy, J. Microsc. 189 (1998), 15-24.

[54] V. Subramaniam, A.K. Kirsch and T.M. Jovin, Cell biological applications of scanning near-field optical microscopy (SNOM), Cell. Mol. Biol. 44 (1998), 689-700.

[55] F.A. Tavassoli and S.J. Schnitt, Pathology of Breast, Elsevier, New York, 1992.

[56] C.M. Taylor, B. Blanchard and D.T. Zava, Estrogen receptormediated and cytotoxic effects of the antiestrogens tamixifen and 4-hydroxytamoxifen, Cancer Res. 44 (1984), 1409-1414.

[57] G.A. Valaskovic, M. Holton and G.H. Morrison, Biological near-field scanning optical microscopy: instrumentation and sample issues for shear-force feedback, Ultramicroscopy $\mathbf{5 7}$ (1995), 212-218.

[58] J.G. Vos, E. Dybing, H.A. Greim, O. Ladefoged, C. Lambre, J.V. Tarazona, I. Brandt and A.D. Veethaak, Health effects of endocrine-disrupting chemicals on wildlife, with special reference to the European situation, Crit. Rev. Toxicol. 30 (2000), 71-133.

[59] W. Wiegräbe, S. Monajembashi, H. Dittmar, K.O. Greulich, S. Hafner, M. Hildebrandt, M. Kittler, B. Lochner and E. Unger, Scanning near-field optical microscope - a method for investigating chromosomes, Surf. Interf. Analyt. 25 (1997), 510-513.

[60] F. Zenhausern, M.P. O'Boyle and H.K. Wickramasinghe, Apertureless near-field optical microscopy, Appl. Phys. Lett. 65 (1994), 1623-1625.

[61] P. Zhang, R. Kopelman and W. Tan, Subwavelength optical microscopy and spectroscopy using near-field optics, Crit. Rev. Sol. State Mat. Sci. 25 (2000), 87-162. 


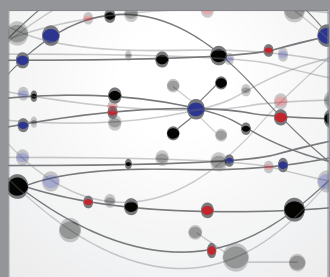

The Scientific World Journal
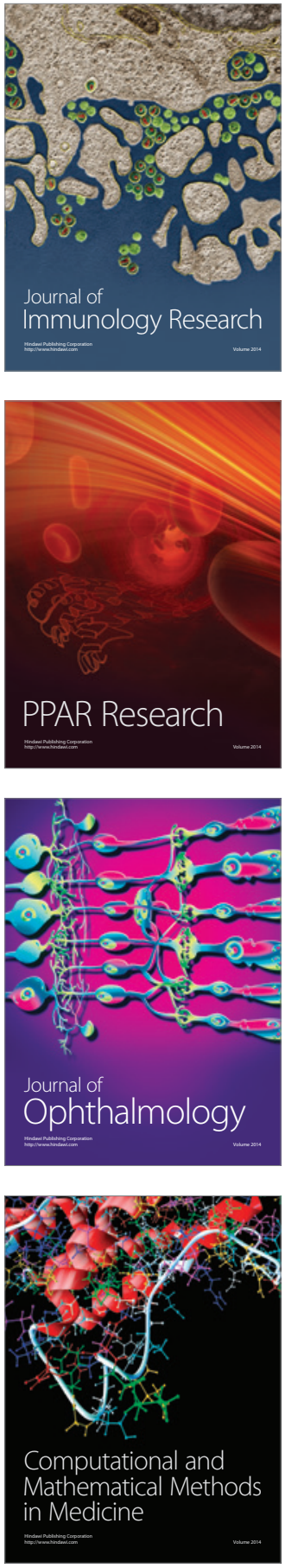

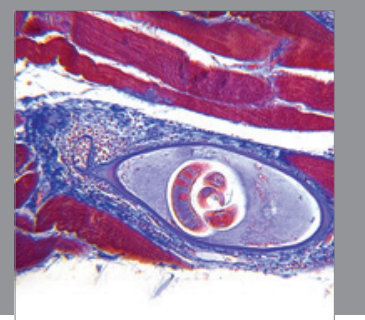

Gastroenterology

Research and Practice
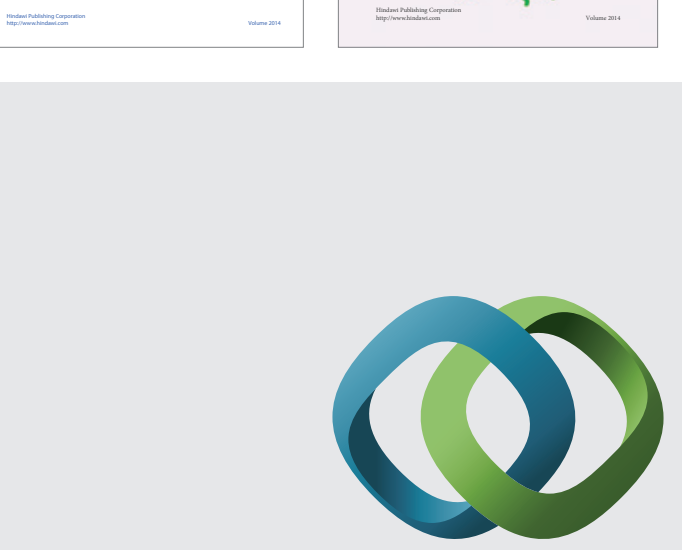

\section{Hindawi}

Submit your manuscripts at

http://www.hindawi.com
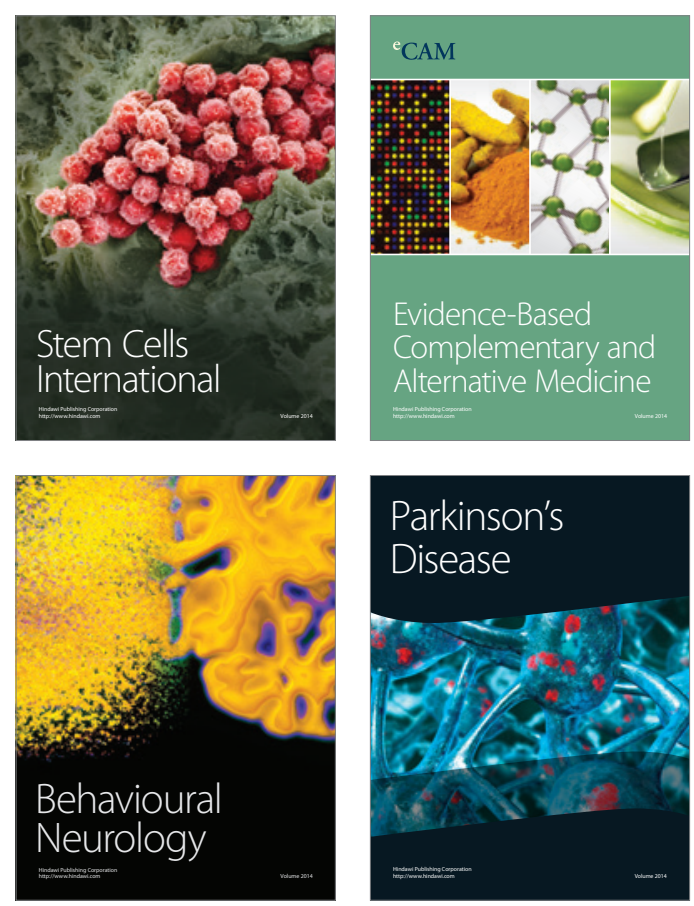

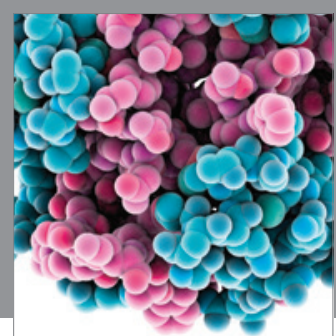

Journal of
Diabetes Research

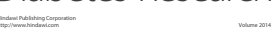

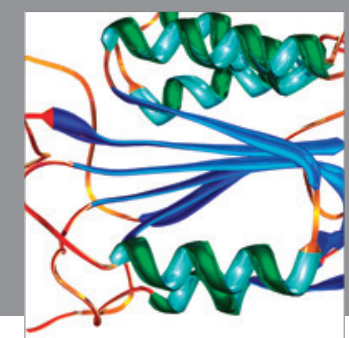

Disease Markers
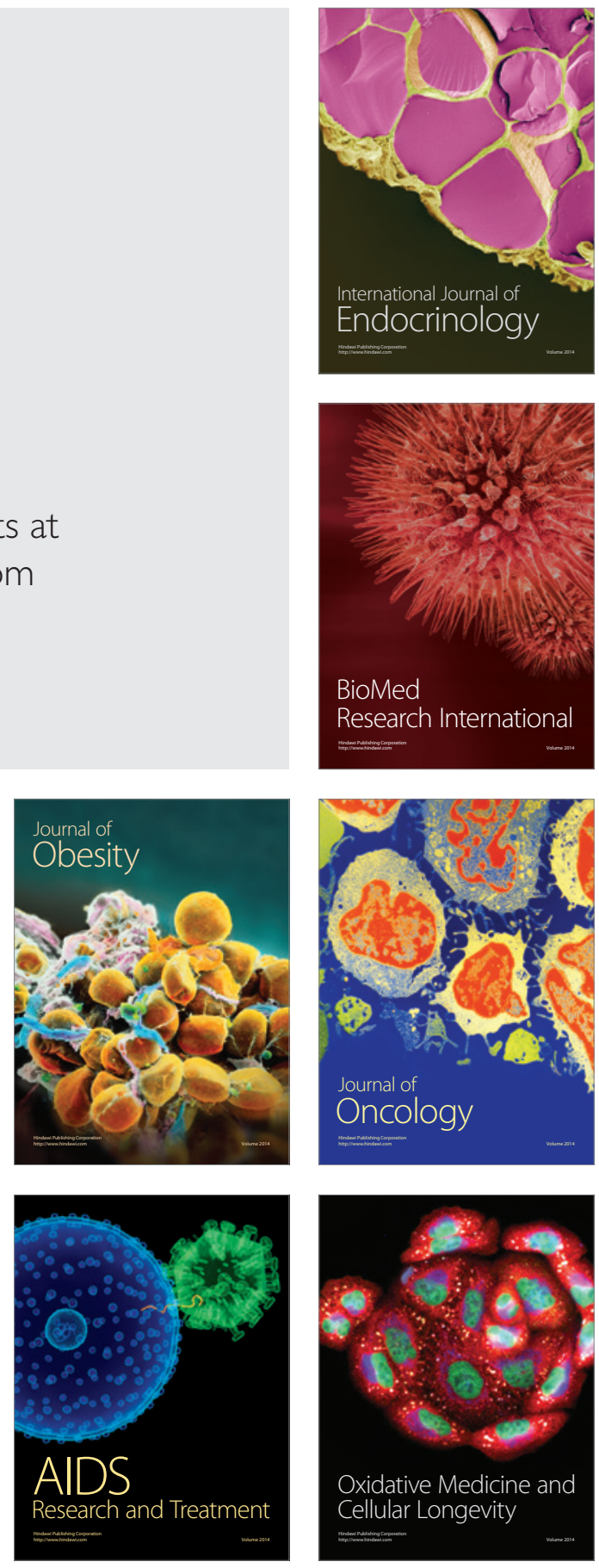